\title{
Citizen Journalism vs. Mainstream Journalism: A Study on Challenges Posed by Amateurs
}

\author{
By Rabia Noor*
}

\begin{abstract}
Citizen journalism is a rapidly evolving form of journalism, which has enabled ordinary people to report newsworthy situations around them. Nowadays mainstream media do not serve as the only source of news. The alternative news sources on the Internet, such as blogs, web portals and social networking sites give a good competition to mainstream media. The current study aims to assess how journalists perceive the impact of citizen journalism on mainstream journalism and their work. It endeavours to find out what challenges, if any, citizen journalism has posed to mainstream media and how does the latter respond to them. A survey was conducted among journalists working in Kashmir that helped to achieve the objectives of the study. The study found that citizen journalism does not pose any imminent threat to mainstream journalism since it is just in its formative years. In fact, citizen journalism holds potential benefits as a source of news. It proves to be useful to bring to fore the stories that are inaccessible to professional journalists.
\end{abstract}

Keywords: citizen journalism, ICT, mainstream journalism, new media, user-generated content

\section{Introduction}

Citizen journalism is a concept in media that refers to journalistic activities of ordinary people. It means citizens themselves report the issues confronting them. Citizen journalism has enabled people to raise their voice on what they feel need attention. These people are, thus, termed as citizen journalists. Duffy, Thorson and Jahng (2010) have defined "citizen journalist" as an individual, who is not a trained professional, but who nonetheless may report on his or her neighborhood or community. Citizen journalists or amateur reporters are none but the general audience, that is, viewers, readers and listeners of mainstream media. Referring to citizen journalists as "people formerly known as the audience," PressThink blogger Jay Rosen (2006) mentions that earlier they would be "on the receiving end of a media system that ran one way, in a broadcasting pattern, with high entry fees and a few firms competing to speak very loudly, while the rest of the population listened in isolation from one another." He, however, argues that presently they are no more in a situation like that.

Citizen journalism is also known as participatory and democratic journalism (Baase, 2008). There are various other synonyms used for citizen journalism "public journalism," "civic journalism," "stand-alone journalism," "networked journalism," "open source journalism," "crowd-sourced journalism," "collaborative journalism," "grassroots journalism," "community journalism," "bridge media" and so on. These forms of journalism are related to "citizen journalism", but each is a unique species that has evolved out of a larger family of social media. All these terms refer to different acts (Cohn, 2007).

\footnotetext{
* Assistant Professor, Islamic University of Science and Technology, India.
} 
One of the most accepted and inclusive definitions of citizen journalism has been put forward by Bowman and Willis (2003) in New Media. They define citizen journalism as the act of non-professionals, playing an active role in the process of collecting, reporting, analysing and disseminating news and information. This definition covers all the possible activities of citizen journalists in existence. The authors further write, "the intent of this participation is to provide independent, reliable, accurate, wide-ranging and relevant information that a democracy requires."

At present various user-generated websites, including news portals and blog sites, are operating across the globe that offer common masses a platform to be citizen journalists and share their stories with rest of the world. Some notable citizen journalism websites of the world include Cable News Network's (CNN) iReport feature that was launched in 2006, Al-Jazeera's Sharek Portal (which means "share") launched in late 2007 (Dreier, 2012), Germany's myHeimat.de, launched in 2005, which has been structured as an aggregated hyperlocal news site (Bruns, 2009) and South Korea's popular and commercially successful online news website OhMyNews, which was founded on February 22, 2000 by Oh Yeon Ho with the motto, "Every Citizen is a Reporter" (The Open News Room, 2011). Over past some years, various citizen journalism news portals have emerged in India as well that include MeriNews, MyNews, Cplash, Cj.IBNLive, INewsIndia and others. The number of citizen journalism sites is constantly increasing as the number of Internet users and new media writers continues to rise.

The study holds much relevance in contemporary times, since citizen journalism has become a trend in media. In fact, it is one of the most novel and talked about trends in journalism at present. What makes it novel is that it is not performed by individuals with professional journalism training, but by ordinary people with no journalism background. Nowadays anyone can be a citizen journalist, since Internet and new media technologies offer unlimited opportunities to upload, and share content for public consumption. Topics that could not make it to traditional media earlier have nowadays unlimited space to be published on citizen journalism sources, especially news portals and blogs. This is why regular followers of citizen journalism content consider it less biased than news content of professional media.

Citizen journalism has been recognised as a powerful force in India, however not many studies have been conducted on the subject in the country. Even though some studies with regard to role and status of citizen journalism in media have been carried on in the recent past, there was a scope for analysing the nature and frequency of updates on citizen journalism sites. The current study has proved useful in that regard. By analysing the nature and frequency of the updates, the study helps to ascertain consistency, and seriousness of citizen journalism news portals in promoting participation of common masses in journalistic activities. It also helps to discuss the emerging and evolving dimension of citizen journalism. Besides, the study helps to find out the challenges that citizen journalism has posed to the mainstream journalism, and also enables one to find out how the later is responding to them. 
In Kashmir, citizen journalism is relatively a new trend. But with the increasing popularity of Internet, the number of non-journalists in the valley sharing news and opinions through blogs and social networking sites is constantly increasing. One of the finest examples of citizen journalism at a regional level could be taken from the massive agitation of 2008 that took place in the Valley in the backdrop of Shri Amarnath land transfer row. It was perhaps for the first time during past over two decades of Kashmir conflict, when a large number of civilians, who took to the streets to stage protests against land transfer to Shri Amarnath Shrine Board, recorded mobilisation of people and whatever they perceived as violation of human rights on their mobile phone cameras to expose alleged atrocities by paramilitary forces before the world. The civilians recorded the pro-freedom protests, stone pelting, firing, tear gas shelling and even killings of several people, especially protestors, on their mobile phone cameras and uploaded the same on the Internet, especially on sites like YouTube and Facebook, to make it available for rest of the world (Noor, 2009).

The trend continued in the succeeding years as well, especially in 2009 following dual murder and rape at Shopian and in 2010 during the Quit-Kashmir movement. The Internet has served as an important medium to reveal the ground situation in Kashmir especially when authorities gagged the mainstream media. Especially during 2010 summer unrest, a complete information blackout was enforced in Kashmir. News channels were barred, while police foiled distribution of newspapers and seized newspaper bundles. Hence, Internet was the sole medium available with people. They used blogs and social networking sites to disseminate the news. Later, however, the Internet too was blocked.

Citizen journalism appears to be catching the hold of print media steadily in Kashmir. One of the leading daily English newspapers of the valley, Greater Kashmir, in 2011 took the initiative of encouraging citizen journalism in Kashmir. Since then the publication has been inviting write-ups and photographs from its readers pertaining to various issues concerning them. The newspaper publishes the citizens' content on its city page under "We the Srinagarites" and "Colony Woes" columns. In January 2014, the publication came up with yet another citizen journalism segment, "Is Anybody Listening?." This way, the Greater Kashmir has pioneered the concept of participatory journalism by print media in Kashmir. In 2013 another English daily newspaper published from Kashmir, Rising Kashmir, invited citizens to file stories, videos and photographs. The citizens' content is published under the "RK CJ Report" column in the city page edition of the publication both in its print and online versions. The stories are mostly related to colony woes, official negligence and events involving public interest. The other local dailies and weeklies are yet to follow the trend. Among online publications, U4UVoice.com became the first citizen journalism website of Jammu and Kashmir in 2013. 


\section{Review of Literature}

It remains uncertain as to where did the term "citizen journalism" come from (Gillmor, 2008). However, it is certain that the term did not exist before the advent of the Internet. Citizen journalism grew in tandem with the growth of the interactive functions on the Internet (The Open News Room, 2011). Tilley and Cokley (2008) mention that the terms "citizen journalist" and "citizen journalism" arose when individuals or groups who were not aligned with publishers as "professional journalists" began to collect, edit and provide publishers with (or publish directly) news material that was out of the publishers' reach. Typically, this material reported sudden events, such as fires, crashes, floods and other disasters, which desk-bound reporters could not attend due to time constraints, or odd on-the-spot items.

As citizen journalism is growing, more and more people are looking at its relationship with mainstream journalism. At the onset of the current millennium, media researchers predicted the demise of mainstream journalism at the hands of citizen journalism. They feared that mainstream journalism shall lose its audience to citizen journalism, since the latter was the creation of the audience itself. However, on the other hand, many scholars dismissed the argument, saying citizen journalism does not have potential to replace professional journalism. The former argument has been supported by Bowman and Willis (2003), who state that the venerable profession of journalism finds itself at a rare moment in history, where, for the first time, its hegemony as gatekeeper of the news is threatened by not just new technology and competitors but, potentially, by the audience it serves.

"Armed with easy-to-use web publishing tools, always-on connections and increasingly powerful mobile devices, the online audience has the means to become an active participant in the creation and dissemination of news and information. And it's doing just that on the Internet."

A similar conclusion has been drawn by the Project for Excellence in Journalism (2008) in their annual report. It has concluded that while a lot of communications researchers and scholars have been "scripting the demise of the profession at the hands of citizen journalists or the contributors," some research suggests that "citizen journalism is an overrated phenomenon."

"The prospects for user-created content once thought possibly central to the next era of journalism, now appear more limited. News people report that the most promising parts of citizen input are new ideas, sources, comments, pictures, and videos. But a citizen posting news content has proved less valuable, with too little that is new or verifiable."

Many scholars, however, have put forward entirely opposite views. Some communication studies have drawn a conclusion that citizen journalism would never be able to replace professional journalism, but can only compliment it. Bentley (2008) affirms that citizen journalism can never replace professional 
journalism. He argues that citizen journalists want people to hear them just because professional journalists are "too busy with the big stories to see the little items that mean so much to people." Former Baltimore Sun reporter and writer/producer of the popular TV series, "The Wire," David Simon (2005) criticizes the concept of citizen journalism - claiming that unpaid bloggers who write as a hobby cannot replace trained, professional, seasoned journalists.

"I am offended to think that anyone, anywhere believes American institutions as insulated, self-preserving and self-justifying as police departments, school systems, legislatures and chief executives can be held to gathered facts by amateurs pursuing the task without compensation, training or, for that matter, sufficient standing to make public officials even care to whom it is they are lying to."

Many researchers have highlighted the citizen journalists' role in supplementing the work of mainstream journalists. They conclude that citizen journalism plays a supportive role in the news-gathering process, thus complementing rather than replacing professional journalism. Deuze, Bruns and Neuberger (2007) investigate the emergence of citizen journalism in Australia, Germany, the Netherlands and the United States to find out how mainstream media is using citizen journalism content.

"For all its success, citizen journalism remains dependent to a significant extent on mainstream news organisations, whose output it debates, critiques, recombines and debunks by harnessing large and distributed communities of users. At the same time, increasingly mainstream news is taking note of what the citizen journalists are saying, and uses content generated by users as an alternative to vox-pops, opinion polls, or in some cases indeed as a partial replacement of editorial work."

Dugan (2008) concluded that citizen journalism could compliment what professional journalists did, but it would not be a replacement for professional reporting nor was it a panacea to the growing reader concerns about traditional media's credibility. Dugan, however, insisted that journalists must be careful to ensure that the ethical standards were followed by both professional and citizen journalists. Xin (2010) came up with a similar finding that citizen journalism was used by mainstream media as a news source or an alternative channel for distributing politically sensitive information, which showed that citizen journalists could work effectively together with mainstream media to expose social injustice cases.

Some studies concluded that mainstream news organisations were exploring the citizen journalism option to stay in competition with rival organisations. Deuze (2007) underlined that editors of traditional news publications were increasingly jumping on the citizen journalism bandwagon so as to stay afloat in journalism business. Media companies, thus, follow new storytelling forms to vie for consumer attention and react to the consumer's 
creation of content with awe and respect. Managing consumer-generated media is increasingly considered critical to commercial survival among business professionals. Newman (2009) concluded that social media and user-generated content were fundamentally changing the nature of breaking news. They are contributing to the compression of the "news cycle" and putting more pressure on editors over what and when to report. The news broadcasters like $B B C$ and $C N N$ place more emphasis on news-related user-generated content and the newsgathering benefits of being closer to their audiences. Newspapers tend to be more interested in engaging audiences over a wider range of non-UGC material in a way that can drive revenue. De Keyser and Raeymaeckers (2011) argued that citizen journalism had forced traditional media to change the relationship with their public. Traditional news media now offer features on their own websites similar to those on the citizen journalism sites. More often the audience feedback is being used to express extreme emotions without putting forward grounded arguments. Kperogi (2011a) observed that while the vigorous profusion of web-based citizen media had the potential to inaugurate an era of dynamic expansion of the deliberative space and even serve as a counterfoil to the domination of the discursive space by the traditional media, a trend was being witnessed towards the aggressive co-optation of these citizen media by corporate media hegemons. The user-generated content sometimes ends up being used in the traditional broadcasts of these stations without any monetary compensation to the originators of the stories. Some communication scholars, in their research work, have suggested to mainstream media to encourage the concept of citizen journalism in their organisations. Bruns, Wilson and Saunders (2009) noted that although false dichotomies between mainstream and citizen journalism were often posed, the best way to attract a community to citizen journalism services was to promote the services in the mainstream media. Any media appearances attract more users and contributions. Being able to syndicate materials in other online forums also helps to draw people to services, which means that contributors get more readers or viewers and more value from their participation. There is a need for a willingness to go beyond the idea that citizen and mainstream journalism are opposed to each another, and instead to consider them as elements of an ecology of "networked journalism," where a range of professional and amateur contributors, and industrial and independent outlets together form the diverse totality of contemporary news production. Tilley and Cokley (2008) observed that the "news media" at present comprised of at least three separate groups of participants: i. professional (i.e., employed) journalists; ii. news publishers, and; iii. "citizen" audience groups, who read, watch, listen to and - importantly - create news content in the form of conventional news and feature articles (or programmes), emails, newsletters, blogs, social networking sites and channels, and a range of other products, such as SMS, MMS, so on and so forth.

Some scholars have raised concern over the challenges posed by citizen journalism to mainstream media. Vanderwagen (2012) studied the impact of Twitter, as a vehicle of citizen journalism, on journalists in South Africa. He argued that the normative role of the journalist as gatekeeper had been challenged 
by citizen journalism and Twitter. Sometime back, citizen journalists utilised Twitter to break and create news in South Africa and globally, resulting in a shift in the way journalists would source and distribute news.

While news is widely available on the social media network, the role of the journalist to be fair, accurate and thorough is heightened by the volume of possible and potentially non-credible news sources. Similarly, Hermida and Thurman (2008) discussed that the news executives at leading UK newspaper websites were providing opportunities for user-generated content, but were experiencing problems with incorporating it into professional journalism structures due to concerns about reputation, trust and legal issues. They also found that there were inconsistencies in the terms used to describe user-generated content formats, despite an attempt to develop taxonomy of generic formats.

According to a study published in the Newspaper Research Journal, citizen journalism sites, including both news sites and blogs, complements rather than substitutes commercial news sites. The study conducted by Lacy, Duffy, Riffe, Thorson, and Fleming (2010) evaluated which sites publish content on a daily basis, and how similar the content is between citizen and mainstream sources. The researchers noted that like weeklies, citizen news and blog sites can serve as complements to daily newspapers.

\section{Objectives}

1. To find out how professional journalists perceive the impact of citizen journalism on mainstream journalism and their work.

2. To find out what challenges, if any, citizen journalism has posed to mainstream journalism.

3. To assess how professional journalists respond to citizen journalism challenges.

4. To find out if citizen journalism content is gaining more popularity among the audience than mainstream news products.

\section{Hypothesis}

H0: There is no significant association between professional experience of mainstream journalists and their views on various aspects of citizen journalism. In other words, irrespective of their journalism experience, professional journalists hold more or less similar views about citizen journalism.

\section{Methodology}

The objectives were achieved by the Survey method, which is one of the most familiar methods in Social Sciences. The primary tool for collection of data was a questionnaire, for it is more economical in terms of time than other tools and 
techniques. During the study, questionnaires were mailed to journalists working in Indian-administered Kashmir, seeking answers from them to questions like what challenges citizen journalism has posed to the mainstream journalism, how they respond to these challenges, whether or not mainstream journalists nowadays have to compete with citizen journalists and if citizen journalism has changed the concept of journalism for better or worse. Questionnaires were distributed in both hard and soft form. Kashmir was selected as an area of research for geographical convenience. The study shall hold relevance for journalists and media scholars from other parts of the world as well, since journalistic ethics are universal.

\section{Questionnaire Design}

The questionnaires comprised of 25 questions that included open as well as close-ended questions. The questionnaire consisted of two sections. In the first section personal information of the journalists was sought, including their name and designation, type of media they worked for (print, broadcast or online), name of organisation, experience (in years), and so on. In the second section, questions pertaining to the current research were asked that helped to achieve the objectives of the study. In close-ended questions, Nominal Scale and Ordinal Scale were used to elicit responses, while in one of the questions, Graphic Scale Rating Scale, and in another the Likert Scale was used.

\section{Sampling}

A stratified sampling method was used for the Survey method. The study encompassed a sample of 50 journalists. The distribution of questionnaires was done on the basis of the experience of the journalists working in various print, television, radio, wire and online organisations in Kashmir. First the population was divided into three strata, viz., freshers (journalists who possess up to five years of journalism experience), mid-career journalists (possessing six to fifteen years of experience) and senior journalists (with over fifteen years of experience). Then random samples were taken from each stratum. From the former two strata, 17 respondents each were randomly selected, while 16 respondents were selected from the third stratum.

\section{Pre-Test of Survey}

The systematic checking or pretesting of a questionnaire is central to planning a good survey. In order to test the validity of the questionnaire, a preliminary survey was conducted among journalists working in Kashmir. Questionnaires were distributed among 10 journalists and their feedback was sought regarding the same. The questions by and large were found to be comprehensible for the journalists, while a few areas of confusion were removed. Some minor changes were made in the format of the questionnaire. The journalists were of the opinion that the data collected through the questionnaire would be reliable to study the impact of citizen journalism on mainstream journalism. 


\section{Statistical Analysis}

The data was coded and entered in the Spreadsheet of SPSS (Statistical Product and Service Solutions) Version 16 software. Various descriptive statistics were employed. The Chi-square test was used in the study to test whether there is any significant association between the experience of journalists and their views on various aspects of citizen journalism with level of significance of 5\%.

\section{Findings}

\section{Personal Information}

Experience. The questionnaires have been distributed among 50 journalists working in Kashmir, divided into three strata on the basis of their journalism experience, viz., freshers, mid-career journalists and senior journalists. The former two strata carry 17 respondents each, while the latter carry 16 respondents.

Designation. Of all journalists surveyed, 29 are reporters/correspondents, 15 are editors and 6 are photojournalists.

Type of media. 33 journalists work for print organisations, 6 for television, 5 for online media, 3 for radio and 3 for wire agencies. Newspaper journalists form the major chunk of the sample since broadcast and new media are yet to flourish at local level in Kashmir.

Media ownership. 35 journalists work for private media organisations, while 15 work for government-owned organisations.

\section{Research-based Information}

Access to new media technologies and CJ content. All the respondents irrespective of their journalism experience have access to new media technologies, as is vivid from Table 1 . Majority of the respondents among senior journalists $(81.3 \%)$, mid-career journalists $(70.6 \%)$ and freshers $(70.6 \%)$ have access to all/most of the forms of new media technologies. Overall, 74\% of the respondents have access to all/most forms of new media technologies. Among the rest of the options, $8 \%$ of the respondents have access to only online communities, $6 \%$ have access to electronic newspapers, while $4 \%$ respondents each have access to mobile computing, multimedia computers and integration of digital data with the telephone such as Internet telephony. In order to ascertain whether there is any association between the experience of the journalists and the forms of new media they access, a Chi-Square test has been conducted. As the p-value is greater than 0.05 (Chi-Square=12.90 and pvalue $=0.22$ ), it suggests that there is an insignificant association between the experience of journalists and the forms of new media technologies they access.

Among the respondents, who were asked for how many years they have access to new media technologies, most of the senior journalist (81.3\%), have access to new media for more than ten years, while the majority of the mid- 
career journalists $(58.8 \%)$ have access to new media for five to ten years and the same percentage of freshers have new media access for less than five years. As the p-value is 0.00 (Chi-Square=33.82), it shows that there is a strong association between the experience of journalists and the access time span, suggesting that more the experience, more is the time of access to new media technologies.

All the respondents surveyed say they access citizen journalism content. As far as the frequency of access to citizen journalism content is concerned, the majority of the freshers (64.7\%), the majority of the mid-career journalists $(52.9 \%)$ and the majority of the senior journalists $(50 \%)$ often access CJ content. Overall $56 \%$ of the respondents often access the citizen journalism content, $26 \%$ respondents rarely access the $\mathrm{CJ}$ content, while $18 \%$ respondents have regular access to it. Here Chi-Square value is 1.07 and p-value is 0.89 , which suggests that there is no association between experience of the journalists and frequency of their access to CJ content.

The majority of the respondents among freshers (52.9\%), mid-career journalists $(41.2 \%)$ and senior journalists $(31.3 \%)$ access citizen journalism content on online media. Of all respondents, $42 \%$ access citizen journalism content on online media. Chi-square value is 4.77 and p-value is 0.57 , which means no association exists between experience of the journalists and medium of access for CJ content.

Almost $69 \%$ of the senior journalists have access to all types of citizen journalism content, followed by $64.7 \%$ freshers and $58.8 \%$ of mid-career journalists, who too access all types of CJ content. Since Chi-Square is 4.49 and pvalue is 0.61 here, there is no association between experience of journalists and type of CJ content accessed.

Citizen journalism vs. traditional journalism. As it is evident from the Table 2, the majority of the senior journalists $(75 \%)$ and the majority of the freshers $(52.9 \%)$ say citizen journalism has changed the concept of journalism for the better. Among mid-career journalists, while 35.3\% respondents say citizen journalism has changed the concept of journalism for the better, another $35.3 \%$ respondents say it has no impact on journalism. The p-value is greater than 0.05 (Chi-Square $=6.36$ and $p$-value $=0.38)$, which suggests that there is no association between the experience of journalists and their views on impact of citizen journalism on the concept of journalism.

A large percentage of freshers $(82.4 \%)$, mid-career journalists $(70.6 \%)$ and senior journalists $(68.8 \%)$ believe citizen journalism does not pose any challenge to mainstream journalism. Overall $74 \%$ of the respondents believe citizen journalism does not pose any challenge to mainstream journalism, while $20 \%$ say citizen journalism poses challenge to it only to some extent and $6 \%$ believe it does pose some challenges to mainstream journalism. As the p-value is greater than 0.05 (Chi-Square $=3.73$ and $p$-value $=0.82$ ), it indicates that there is no association between the experience of journalists and their views on challenges posed to journalism by citizen journalism. 
Table 1. Access to New Media Technologies and CJ Content

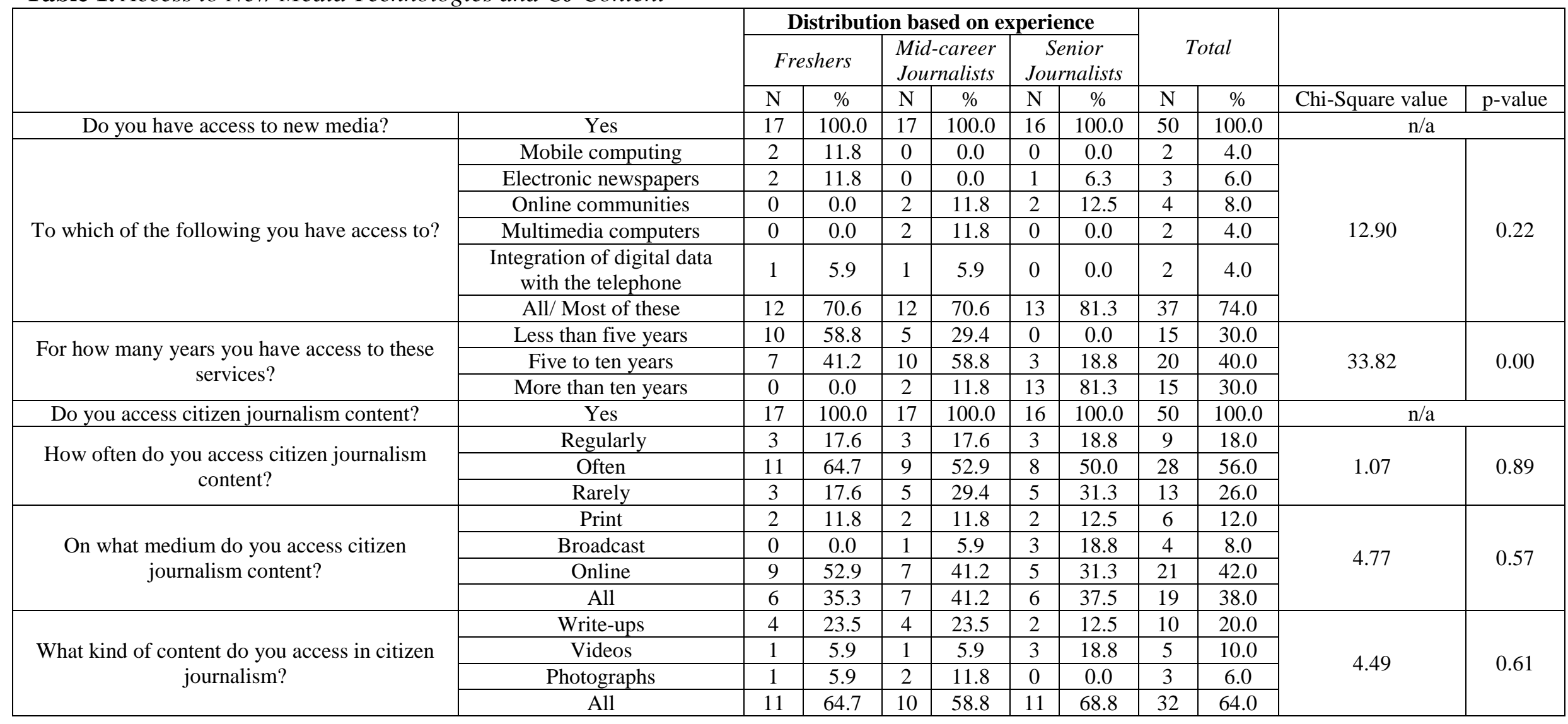


Table 2. Citizen Journalism vs. Traditional Journalism

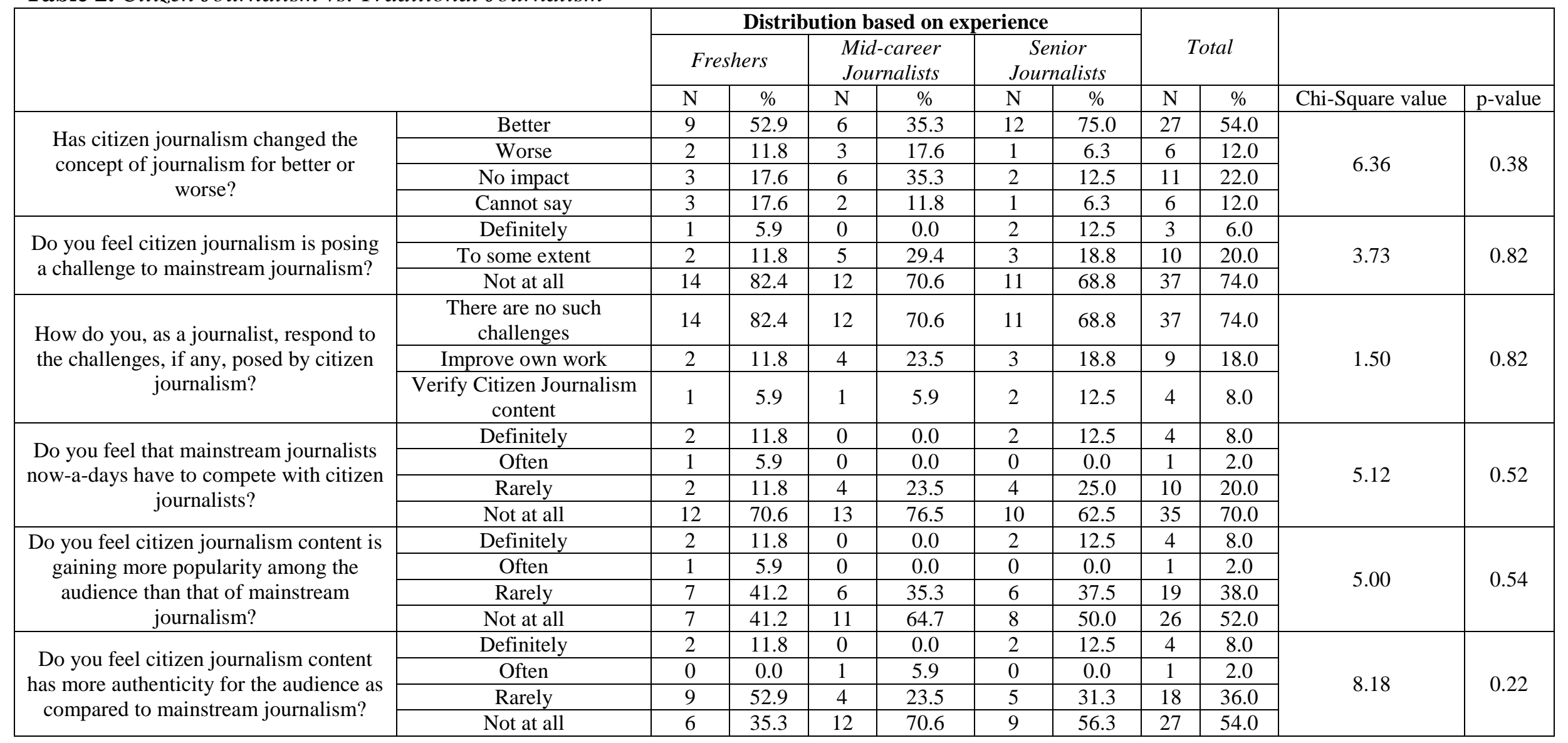


The majority of the freshers $(82.4 \%)$, mid-career journalists $(70.6 \%)$ and senior journalists $(68.8 \%)$ do not see citizen journalism as a challenge to mainstream journalism. Instead, $74 \%$ of the respondents (overall) believe that citizen journalism is supplementing the work of mainstream journalists. 18 percent of the respondents say so as to deal with the challenges posed by citizen journalism they would try and bring improvement in their own work. They will enhance their professional skills, improve the quality of their news products and accelerate the mode of their work so as to come up with exclusive news stories. 8 percent of the respondents say they would further cross-check the facts presented by the citizen journalists and come up with research-based stories. They would get to the news venue and verify the authenticity of citizen journalism content and sources. Here, Chi-Square value is 1.50 and p-value is 0.82 , which suggests that there is no association between the experience of professional journalists and their response to citizen journalism challenges.

Most of the mid-career journalists $(76.5 \%)$, freshers $(70.6 \%)$ and senior journalists $(62.5 \%)$ say they do not have to compete with citizen journalists. Overall, $70 \%$ respondent say they do not feel any competition with citizen journalists, while $20 \%$ feel they rarely have to compete with them. Only $8 \%$ of the respondents say they have to compete with citizen journalists. The ChiSquare value is 5.12, while the p-value is 0.52 . This suggests that there is no association between the experience of the journalists and their competition with citizen journalists.

The majority of mid-career journalists $(64.7 \%)$ and senior journalists $(50 \%)$ do not believe that citizen journalism content is gaining more popularity among the audience in comparison to that of mainstream journalism. Among freshers, $41.2 \%$ say citizen journalism becomes popular with the audience on rare occasions, while another $41.2 \%$ respondents say it has not gained more popularity than mainstream journalism. Chi-Square value is 5.00 , while the pvalue is 0.54 , suggesting that there is no association between the experience of journalists and their views of popularity of citizen journalism content.

The majority of the mid-career journalists $(70.6 \%)$ and senior journalists (56.3\%) say citizen journalism content does not have more authenticity for the audience as compared to that of mainstream journalism, while most of the freshers $(52.9 \%)$ say it does have on rare occasions. Since Chi-Square value is 8.18 and $p$-value is 0.22 , hence there is no association between the experience of journalists and their views on the authenticity of citizen journalism content.

Quality of CJ content. The majority of the senior journalists (75\%), midcareer journalists $(82.4 \%)$ and freshers $(70.6 \%)$ do not have knowledge about breaking news by citizen journalists that was later followed in traditional media. The Chi-Square value is 0.65 and $\mathrm{p}$-value is 0.72 , suggesting that there is no association between the experience of the journalists and their awareness about breaking news stories by citizen journalists.

The respondents who are able to recall breaking news stories by citizen journalists mainly point towards the stories from the "Arab Spring Movement" that were broken by citizen journalists mostly on social media. The stories swept many countries. Even today, many stories coming from strife-torn Syria 
and Bahrain are broken by citizen journalists active in those countries. Some respondents refer to the videos and pictures taken by amateurs during the tsunami that had hit countries including Indonesia in 2005. They provided a close-up view of the devastation much before the professional journalists could reach the affected areas. Some respondents have also mentioned corruption cases exposed by citizen journalists through "Right to Information (RTI) movement." For instance a story headlined "Ghost Employees in MCD" was exposed by a citizen journalist in Delhi through RTI.

One of the respondents points to the stories uploaded by citizen journalists on social networking sites, in the form of videos, photographs and text, during the mass uprising in Indian-administered Kashmir in 2008 and 2010. The posts mainly highlighted stone pelting incidents and killings that took place in Kashmir during the unrest. Many a time the news was found later in the traditional media. Some other breaking news stories include "forest fire in Kumaon," "mafia-government nexus," "molestation of a girl at Jaipur police station" and "burning of a bear by people of a remote village at Tral in South Kashmir."

Among all three categories, the majority of the respondents feel that the citizen journalism content is of average quality, viz., $75 \%$ of senior journalists, $70.6 \%$ freshers and $52.9 \%$ mid-career journalists. Overall, $66 \%$ respondents find citizen journalism content of average quality. The Chi-Square value is 3.59 and the $\mathrm{p}$-value is 0.46 , which suggests that there is no association between the experience of the journalists and their opinion on quality of citizen journalism content.

75 percent of the senior journalists, and $64.7 \%$ each among freshers and midcareer journalists rarely find citizen journalism content credible. Overall, 68\% respondents find citizen journalism content credible only on rare occasions. The pvalue here is $0.97 \%$ that suggests that there is no association between the experience of the journalists and their views on credibility of citizen journalism content.

The majority of the respondents, viz., $82.4 \%$ mid-career journalists, $68.8 \%$ senior journalists and $64.7 \%$ freshers, feel citizen journalism content rarely possesses news values. Overall, $72 \%$ of the respondents say citizen journalism content possesses news values on rare occasions. The Chi-square value being 5.17 and p-value being 0.52 suggests that no association exists between journalists' experience and their understanding of newsworthiness of citizen journalism content.

76.5 percent freshers and $62.5 \%$ senior journalists feel citizen journalists rarely follow journalistic ethics. Among mid-career journalists, while 47.1\% respondents say citizen journalists rarely follow journalistic ethics, another $47.1 \%$ respondents say they never do. The p-value here is 0.36 (Chi-square=6.55), which suggests that there is no association between the experience of the journalists and their views on whether citizen journalists follow journalistic ethics.

The majority of the freshers $(58.8 \%)$ and mid-career journalists $(41.2 \%)$ have rarely come across the citizen journalism content, which they feel is unethical, while most of the senior journalists (37.5\%) have never come across such content. The Chi-square value here is 10.95 and the p-value is 0.09 , which suggests that not a very strong association exists between the professional 
experience of the journalists and their experience with unethical citizen journalism content. The detailed analysis is vivid from Table 3.

Among the respondents, who have come across unethical citizen journalism content, some have referred to the infamous uploading of "fake videos by the Aljazeera channel." The channel would broadcast the videos of continuous bombardment in Syria uploaded by citizen journalists. Later the same channel disclosed that the videos were fake. In fact, in order to build a pro-crises agenda, the rebels, masquerading as citizen journalists, would pile up rubber tyres on the terraces of the buildings and set them on fire. Then they would make the video clips through mobile sets and eventually upload them on the Internet, which many channels were showing to prove that the bombing was continuously taking place. The channel later apologized for the same. The respondents have mentioned some other incidents as well. For instance, a citizen journalist had uploaded on the Internet some nude photographs of a village woman, whom villagers considered a witch and thus punished her out of ignorance. Another citizen journalist had reported that a nine-year-old child was killed and three others injured in an accident at Dadasara Tral in South Kashmir. The story was later found to be fake.

Future of citizen journalism. As evident from Table 4, the majority of the respondents, viz., $76.5 \%$ freshers, $70.6 \%$ mid-career journalists and $62.5 \%$ senior journalists believe that applying gatekeeping to citizen journalism content can ensure its credibility. Overall, $70 \%$ of the respondents insist upon gatekeeping of citizen journalism content. 22 percent of the respondents suggest that citizen journalists should be taught the basic journalistic ethics to ensure credibility of the citizen journalism content. 4 percent of the respondents insist upon receiving feedback from the audience about the quality of the citizen journalism content, while another $4 \%$ of the respondents believe it is not possible at all to ensure credibility of citizen journalism content. The Chi-square value being 3.59 and the p-value being 0.75 does not suggest any strong association between journalists' experience and their views on how to ensure credibility of citizen journalism content.

The respondents have come up with mixed views on whether some restrictions should be imposed on the citizen journalism content. While $41.2 \%$ of the mid-career journalists say there should be some restrictions on the citizen journalism content, $35.3 \%$ of the freshers believe no restrictions/censorship should be imposed on the content. Among senior journalists, 37.5\% respondents say restrictions should be imposed only to some extent, while another $37.5 \%$ respondents believe there should not be any restrictions on citizen journalism content. The p-value here is 0.70 (Chi-square=3.75), which suggests that there does not exist a strong association between the experience of the journalists and their views on whether or not restrictions should be imposed on citizen journalism content. 
Table 3. Quality of CJ Content

\begin{tabular}{|c|c|c|c|c|c|c|c|c|c|c|c|}
\hline & & \multicolumn{6}{|c|}{ Distribution based on experience } & \multirow{2}{*}{\multicolumn{2}{|c|}{ Total }} & & \\
\hline & & \multicolumn{2}{|c|}{ Freshers } & \multicolumn{2}{|c|}{$\begin{array}{l}\text { Mid-career } \\
\text { Journalists }\end{array}$} & \multicolumn{2}{|c|}{$\begin{array}{c}\text { Senior } \\
\text { Journalists } \\
\end{array}$} & & & & \\
\hline & & $\mathrm{N}$ & $\%$ & $\mathrm{~N}$ & $\%$ & $\mathrm{~N}$ & $\%$ & $\mathrm{~N}$ & $\%$ & Chi-Square value & p-value \\
\hline \multirow{2}{*}{$\begin{array}{l}\text { Can you recall any breaking news by a citizen journalist } \\
\text { that was later followed in traditional media? }\end{array}$} & Yes & 5 & 29.4 & 3 & 17.6 & 4 & 25.0 & 12 & 24.0 & \multirow{2}{*}{0.65} & \multirow{2}{*}{0.72} \\
\hline & No & 12 & 70.6 & 14 & 82.4 & 12 & 75.0 & 38 & 76.0 & & \\
\hline \multirow{3}{*}{ How do you find quality of citizen journalism content? } & Good & 2 & 11.8 & 2 & 11.8 & 0 & 0.0 & 4 & 8.0 & \multirow{3}{*}{3.59} & \multirow{3}{*}{0.46} \\
\hline & Average & 12 & 70.6 & 9 & 52.9 & 12 & 75.0 & 33 & 66.0 & & \\
\hline & Poor & 3 & 17.6 & 6 & 35.3 & 4 & 25.0 & 13 & 26.0 & & \\
\hline \multirow{4}{*}{ Do you find citizen journalism content credible? } & Definitely & 1 & 5.9 & 1 & 5.9 & 1 & 6.3 & 3 & 6.0 & \multirow{4}{*}{1.18} & \multirow{4}{*}{0.97} \\
\hline & Often & 2 & 11.8 & 1 & 5.9 & 1 & 6.3 & 4 & 8.0 & & \\
\hline & Rarely & 11 & 64.7 & 11 & 64.7 & 12 & 75.0 & 34 & 68.0 & & \\
\hline & Not at all & 3 & 17.6 & 4 & 23.5 & 2 & 12.5 & 9 & 18.0 & & \\
\hline \multirow{4}{*}{$\begin{array}{l}\text { Do you feel citizen journalism content possesses news } \\
\text { values? }\end{array}$} & Definitely & 2 & 11.8 & 0 & 0.0 & 0 & 0.0 & 2 & 4.0 & \multirow{4}{*}{5.17} & \multirow{4}{*}{0.52} \\
\hline & Often & 1 & 5.9 & 1 & 5.9 & 2 & 12.5 & 4 & 8.0 & & \\
\hline & Rarely & 11 & 64.7 & 14 & 82.4 & 11 & 68.8 & 36 & 72.0 & & \\
\hline & Not at all & 3 & 17.6 & 2 & 11.8 & 3 & 18.8 & 8 & 16.0 & & \\
\hline \multirow{4}{*}{ Do you feel citizen journalists follow journalistic ethics? } & Definitely & 0 & 0.0 & 0 & 0.0 & 1 & 6.3 & 1 & 2.0 & \multirow{4}{*}{6.55} & \multirow{4}{*}{0.36} \\
\hline & Often & 1 & 5.9 & 1 & 5.9 & 0 & 0.0 & 2 & 4.0 & & \\
\hline & Rarely & 13 & 76.5 & 8 & 47.1 & 10 & 62.5 & 31 & 62.0 & & \\
\hline & Not at all & 3 & 17.6 & 8 & 47.1 & 5 & 31.3 & 16 & 32.0 & & \\
\hline \multirow{4}{*}{$\begin{array}{l}\text { Do you come across citizen journalism content that you } \\
\text { feel is unethical? }\end{array}$} & Regularly & 4 & 23.5 & 3 & 17.6 & 5 & 31.3 & 12 & 24.0 & \multirow{4}{*}{10.95} & \multirow{4}{*}{0.09} \\
\hline & Often & 2 & 11.8 & 5 & 29.4 & 2 & 12.5 & 9 & 18.0 & & \\
\hline & Rarely & 10 & 58.8 & 7 & 41.2 & 3 & 18.8 & 20 & 40.0 & & \\
\hline & Never & 1 & 5.9 & 2 & 11.8 & 6 & 37.5 & 9 & 18.0 & & \\
\hline
\end{tabular}


Table 4. Future of Citizen Journalism

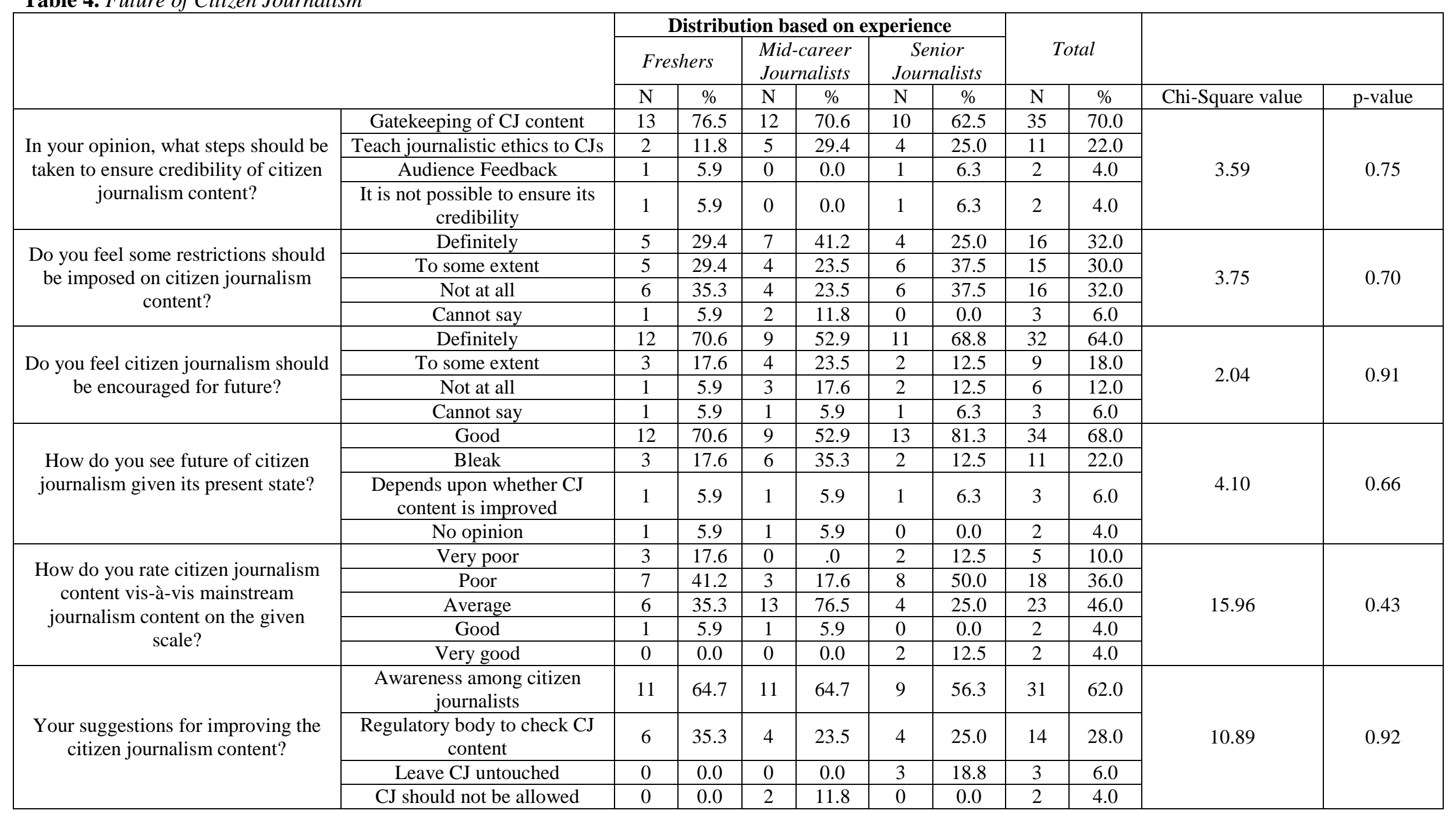


The majority of the respondents, viz., freshers (70.6\%), senior journalists $(68.8 \%)$ and mid-career journalists $(52.9 \%)$ feel citizen journalism should be definitely encouraged for the future. Overall, $64 \%$ of the respondents believe it should be encouraged, while $18 \%$ say it should be encouraged only to some extent and $12 \%$ say it should not be encouraged at all. Here the p-value is 0.91 (Chisquare $=2.04$ ) suggesting that there is no association between the experience of the journalists and their views on whether or not citizen journalism should be encouraged for future.

81.3 percent of the senior journalists, $70.6 \%$ of the freshers and $52.9 \%$ of the mid-career journalists believe citizen journalism is going to stay in future given the advances in new media technologies. Overall, $68 \%$ of the respondents predict good future for citizen journalism. $22 \%$ respondents say citizen journalism does not have a bright future, rather a bleak one. They believe it will take a long time to grow, and could be, in fact, discouraged by the governments. 6 percent of respondents say the future of citizen journalism depends upon whether or not its content is improved. They believe the improvement can be brought upon by the gatekeeping of the content. 4 percent of the respondents hold no opinion in this regard. Here the Chi-square value is 4.10 and the p-value is 0.66 , which does not suggest a very strong association between the experience of the journalists and their views on future of citizen journalism.

The majority of the mid-career journalists $(76.5 \%)$ have rated the citizen journalism content " 3 " vis-à-vis mainstream journalism content on the scale of 5, where 3 signifies "average." Most of the freshers (41.2\%) and senior journalists $(50 \%)$ have rated it "2" that signifies "poor." The Chi-Square value being 15.96 and p-value being 0.43 suggests that not a very strong association exists between the experience of the journalists and their views of quality of citizen journalism content in comparison to that of mainstream journalism.

The majority of the respondents, viz., freshers $(64.7 \%)$, mid-career journalists $(64.7 \%)$ and senior journalists $(56.3 \%)$ are mainly of the view that there is a need to create awareness about various aspects of journalism profession including various laws governing news content among potential citizen journalists. It could be in the shape of dos and do not aired or broadcast by the mainstream media for their benefit. The respondents believe that there must be some short-term or specialized training courses available for them. They must be given an idea of the newsroom atmosphere and work culture of media. Overall, $62 \%$ respondents hold such views. $28 \%$ respondents suggest to constitute a regulatory body to check citizen journalism content, while $6 \%$ respondents say the $\mathrm{CJ}$ content should be published in its original form so as to bring "real" stories to fore. Here the p-value is 0.92 (Chi-square=10.89) that does not suggest any association between the experience of the journalists and their suggestions for improving the citizen journalism content.

Thus, the null hypothesis that "there is no significant association between professional experience of mainstream journalists and their views on various aspects of citizen journalism" has been proved correct in Chi-square test conducted during the study. 


\section{Conclusion}

The data collected during the study reveals that not many challenges are posed by citizen journalism to mainstream journalism. The majority of the journalists, irrespective of their journalism experience, believe that citizen journalism does not pose any imminent threat to mainstream journalism since it is just in its formative years. Mainstream media is believed to enjoy more authenticity and credibility among the audience because of its elaborate and wellestablished system of functioning, in which the emphasis remains on accuracy and responsibility. The audience prefers news products by professional journalists over the citizen journalism content. This is a clear indication that citizen journalism can never replace professional journalism, but can only complement it. So the thought that professional journalists nowadays have to compete with citizen journalists is nothing but a myth. The main difference between mainstream journalism and citizen journalism is voluntary nature of work. Citizen journalism is participatory in nature while mainstream journalism is highly professional. The latter is more than mere reporting of facts. So any person with a pen or camera in hand cannot become a professional journalist unless trained in skills of observation, understanding, expression and responsibility. Citizen journalism content is usually of average quality and rarely possesses news values, while citizen journalists rarely follow journalistic ethics. This also reduces the threat of citizen journalism to mainstream journalism.

The biggest challenge seen by some respondents is that citizen journalists can sometimes break news on the Internet even before professional journalists. This has reduced the dependability of the general audience on mainstream media. Some respondents say even if they have not come across breaking news stories by citizen journalists, there are instances where the content provided by them has become the first clue for professional journalists' stories. At times, a sense of insecurity creeps in the professional journalists when they see citizen journalists breaking the stories and hogging the limelight. But instead of seeing it as a threat, it must be seen as an opportunity to raise the bar further and bring an improvement in one's own work. The best response to challenges, if any, posed by citizen journalists to professionals is to encourage them to do better, and work in tandem with them for bigger and greater impact. Citizen journalism has been and can always be used as a news source by mainstream media. It supplements the work of mainstream journalists. Citizen journalists scratch the surface, while professional journalists move in to complete the job. Even though citizen journalists have come up with some breaking news stories on certain occasions, mainstream journalists still enjoy more credibility, authenticity and popularity among the audience than the former.

The maximum number of respondents suggest citizen journalism should be encouraged for the future and believe that it is going to stay given the advances in new media technologies, such as camera phones, camcorders, blogs, social networking and media-sharing websites, and so on. Citizen journalism, in the coming days, is believed to become more accessible to people worldwide, since more and more people are becoming techno-savvy. Besides, some established 
news organisations, like $C N N-I B N$ and others give a good space to citizen journalism content and seek citizen inputs (text/photos) about public issues. So citizen journalism is believed to grow in future with mainstream media outlets constantly encouraging it.

The majority of the respondents surveyed feel that citizen journalism has changed the concept of journalism for the better. It provides ordinary citizens with an opportunity to highlight the genuine issues that may be skipped by professional journalists. Citizen journalism, thus, adds value to the mainstream news coverage by bringing to light the issues at the grassroots level that are otherwise overlooked by big media outlets. Nowadays even reputed media organisations use citizen journalism content in their newscasts and documentaries. The content is believed to hold high significance in the contemporary times, even if its quality is low. Citizen journalism is a pathbreaking concept that makes a consumer a contributor. It gives citizens the power to express themselves and participate in social and political change.

Contrarily, some respondents have presented the other side of citizen journalism. They believe it has had more negative than positive effects on the concept of journalism. It has given rise to what some people call "journalism of assertion." It means unsubstantiated opinion and rumor is passed on as fact, which harms journalistic credibility. There is also lack of restraint among online writers. The citizen journalists may violate the ethical standards and sensationalize stories in the absence of gatekeeping. There is also confusion as to whom to call a journalist, when anyone can publish. Citizen journalists do not abide to the traditional news values. They also show little knowledge of concepts like newsworthiness. Since they are not obliged to follow the framework of traditional media, their works tend to be less credible. Besides, there is a tendency of plagiarism as far as citizen journalism content is concerned. At times citizen journalists have also been found to upload unethical content. Some respondents say citizen journalists tend to focus only on one side of the issue or development, hence making the story unbalanced. The stories are heavily slanted in some cases. Citizen journalists many a time sensationalize things in an unethical manner. In quite some cases, one can find a citizen journalist transgressing ethical, professional and even legal standards either out of ignorance or willfully with malicious intent.

Most of the respondents believe that implementation of gatekeeping to citizen journalism content is a must to ensure its credibility. They stress upon having a proper mechanism to filter the news content, be it in the form of text or images, posted by citizen journalists. The details presented by citizen journalists should be verified and cross-checked from multiple sources and edited by professional editors before making them public. The job of citizen journalists must be to lead mainstream journalists to news that is inaccessible to the latter. Some respondents suggest that citizen journalists should be taught the basic and the most vital journalistic ethics to ensure credibility of the citizen journalism content. The organisations offering citizen journalism platform, be it websites, television news channels or newspapers, should start journalism classes for citizen journalists to educate them with journalistic ethics. The need for accurate, fair and balanced 
dispatches should be emphasized. Some respondents suggest that an independent body should be constituted to check the authenticity of the information drafted by citizen journalists.

All the journalists surveyed have access to new media technologies, while the majority of them access all/most of the forms of new media technologies. Most of the respondents have access to new media from five to ten years. Besides, majority of the respondents often access citizen journalism content, with most of them accessing the content on online media. The majority of the respondents have access to all types of citizen journalism content, which specifies a growing inclination of journalists towards a democratic journalistic platform in the form of citizen journalism.

\section{Limitations of Study}

The study encompassed a small sample of 50 journalists for this was an exploratory study and a very first of its kind in Kashmir. Since only journalists from Kashmir were questioned, the results may not be generalized.

\section{References}

Baase, S. (2008). A Gift of Fire (3rd ed.). Lebanon: Prentice Hall.

Bentley, C. H. (2008). Citizen Journalism: Back to the Future. Discussion paper presented at the Carnegie Knight Conference on the Future of Journalism, Cambridge, MA. Retrieved from goo.gl/jCCfgv. [Accessed: $9^{\text {th }}$ November 2013]

Bowman, S., \& Willis, C. (2003). We Media: How Audiences are Shaping the Future of News and Information. A Seminal Report. Reston: The Media Centre at the American Press Institute. Retrieved from goo.gl/WSjaZc. [Accessed: $26^{\text {th }}$ October 2013]

Bruns, A. (2009). Citizen Journalism and Everyday Life: A Case Study of Germany's myHeimat.de. Paper presented at Future of Journalism Conference, Cardiff. Retrieved from goo.gl/0kcZA2. [Accessed: $26^{\text {th }}$ October 2013]

Bruns, A., Wilson, J., \& Saunders, B. (2009). Citizen Journalism as Social Networking: Reporting the 2007 Australian Federal Election. In S. Allan \& E. Thorsen (Eds.), Citizen Journalism: Global Perspectives (pp. 197-208). New York: Peter Lang Publishing Group.

Cohn, D. (2007). Time Citizen Journalism Pulled Its Acts Together. Retrieved from goo.gl/ExN9LH. [Accessed: $30^{\text {th }}$ October 2013]

De Keyser, J., \& Raeymaeckers, K. (2011, May 25). The Printed Rise of the Common Man. Paper presented at the Annual Meeting of the International Communication Association, Boston, MA.

Deuze, M. (2007). Cultural Convergence in the Creative Industries. International Journal of Cultural Studies, 10(2), 243-263.

Deuze, M., Bruns, A., \& Neuberger, C. (2007). Preparing for an Age of Participatory News. Journalism Practice, 1(3), 322-338.

Dreier, T. (2012). Al-Jazeera Enables Citizen Journalism With Online Video. Streaming Media Magazine. Retrieved from goo.gl/1MRcD. [Accessed: $4^{\text {th }}$ November 2013] 
Duffy, M., Thorson, E., \& Jahng, M. (2010). Comparing Legacy News Sites with Citizen News and Blog Sites: Where is the Best Journalism? Paper presented at the Annual Meeting of the International Communication Association, International Convention and Exhibition Centre, Suntec City, Singapore.

Dugan, M. A. (2008). Journalism Ethics and the Independent Journalist. McGeorge Law Review, 39(3), 801-811.

Gillmor, D. (2008). Where Did "Citizen Journalist" Come From? Retrieved from goo.gl/ou36Df. [Accessed: $6^{\text {th }}$ November 2013]

Hermida, A., \& Thurman, N. (2008). Researching the Attitudes of Online News Editors towards Participatory Journalism. Paper presented at the Annual Meeting of the International Communication Association, Montreal, Quebec, Canada.

Kperogi, F. (2011). Cooperation with the Corporation? CNN and the Hegemonic Cooptation of Citizen Journalism through iReport.com. New Media \& Society, 13(2), 314-329.

Lacy, S., Duffy, M., Riffe, D., Thorson, E., \& Fleming, K. (2010). Citizen Journalism Web Sites Complement Newspapers. Newspaper Research Journal, 31(2), 34-46.

Newman, N. (2009, September). The Rise of Social Media And Its Impact on Mainstream Journalism: A Study of How Newspapers And Broadcasters in the UK And US are Responding to A Wave of Participatory Social Media, And A Historic Shift in Control Towards Individual Consumers. Reuters Institute for the Study of Journalism, University of Oxford. Retrieved from goo.gl/UI8569.

Noor, R. (2009). Advocacy Journalism: A Study of Greater Kashmir's Save Dal Campaign (2004-2007) (pp. 9-10) (Unpublished doctoral dissertation). Media Education Research Centre, University of Kashmir, Srinagar, India.

Project for Excellence in Journalism. (2008). The State of The News Media: An Annual Report on American Journalism. Retrieved from goo.gl/0578ME. [Accessed: $9^{\text {th }}$ November 2013].

Rosen, J. (2006). The People Formerly Known as the Audience. PressThink. Retrieved from goo.gl/6tOI8z. [Accessed: $12^{\text {th }}$ November 2013].

Simon, D. (2005). Wire Creator David Simon Testifies on the Future of Journalism. Retrieved from goo.gl/BfCWKa. [Accessed: $16^{\text {th }}$ November 2013].

The Open News Room. (2011). Citizen Journalism: A Primer on the Definition, Risks and Benefits, and Main Debates in Media Communications Research. Retrieved from goo.gl/y4IwV8. [Accessed: $20^{\text {th }}$ November 2013].

Tilley, E., \& Cokley, J. (2008). Deconstructing the Discourse of Citizens Journalism: Who Says What and Why It Matters. Pacific Journalism Review, 14(1).

Vanderwagen, C. (2012). How Twitter is Impacting Professional Journalism in South Africa. Published on Academia.edu.

Xin, X. (2010, June 21). The Role of Citizen Journalism in China's Changing Media and Social Environment. Paper presented at the Annual Meeting of the International Communication Association, International Convention and Exhibition Centre, Suntec City, Singapore. 